\title{
Possible future of induced sputum in interstitial lung disease
}

\author{
E. Fireman*, Y. Lerman**
}

The search for noninvasive means of retrieving cells and soluble material from the lung has gained momentum over the past few years. Induced sputum is a particularly promising procedure since it provides specific information on both the cellular and soluble constituents in airways inflammation. It was first used to investigate lung cancer and respiratory infections $[1,2]$, and later to diagnose Pneumocystis carinii pneumonia in patients infected with human immunodeficiency virus [3]. More recently, the method was modified to study asthmatics by focusing on several markers of inflammation [4] as well as to investigate the pathogenesis, pathophysiology and treatment of asthma in general $[5,6]$ and, more specifically, of occupational asthma [7]. The information on cell composition provided by induced sputum was also found to be of value in managing chronic airflow limitation [8].

The fibreoptic bronchoscope and the development of bronchoalveolar lavage (BAL) have facilitated the methodology for sampling the inflammatory response in patients with interstitial lung diseases (ILDs). BAL is useful in the diagnosis of specific conditions, staging the extent of diseases and, in some cases, predicting response to treatment $[9,10]$. Although this is an essentially noninvasive procedure when carried out under proper selection guidelines and bears minimal risk, patient compliance is a commonly encountered problem and BAL is impractical for screening and repeated sampling. Moreover, it cannot be performed on patients who suffer from other diseases which contraindicate bronchoscopy.

In contrast to BAL, the induced sputum procedure is far easier to carry out, is entirely noninvasive, and can be frequently performed in order to follow the dynamic course of pulmonary inflammatory disease and the effect of treatment. The question is whether or not it can provide the same information as BAL and, eventually, replace it in certain conditions.

The last 5 yrs have witnessed the publication of the initial findings of several studies comparing samples of lung material collected by means of sputum induction and by means of BAL in healthy subjects, patients with asthma and patients with chronic bronchitis $[11,12]$. However, the first studies comparing induced sputum with BAL in ILD were published only a few months ago, when the authors' group reported that induced sputum may reveal status

*Institute of Pulmonary and Allergic Diseases, Tel Aviv Sourasky Medical Center and the Sackler Faculty of Medicine, Tel Aviv University, Tel Aviv, Israel. **The Occupational Health and Rehabilitation Institute, Ra'anana, Israel.

Correspondence: E. Fireman, Institute of Pulmonary and Allergic Diseases, Tel Aviv Sourasky Medical Center, 6 Weizman Street, Tel Aviv 64239, Israel. Fax: 97236974601 with respect to hazardous dust exposure as effectively as BAL [13], and that induced sputum is comparable to BAL for the evaluation of patients with sarcoidosis and nongranulomatous ILD [14]. In parallel, other investigators compared induced sputum to bronchial wash and BAL in patients newly diagnosed as having sarcoidosis [15]. Moreover, it was recently shown that pulmonary involvement can also be demonstrated in patients with Crohn's disease via the accumulation of CD4+ T-cells in induced sputum [16].

The authors were able to benefit from the plethora of studies performed on the methodology of induction and processing of induced sputum in asthmatic patients and validate them in patients with ILDs. An ultrasonic nebulizer, reportedly more likely to be successful than other jet nebulizers [17], was used. Only $8 \mathrm{~mL}$ of hypertonic saline were used since this produces the same recovery of sputum, less discomfort to the patient and less of an increase in the levels of neutrophils than do larger doses [18].

As for the safety of sputum induction, it was found to be free of risk in patients with asthma of varying severity $[19$, $20]$ and in patients with chronic obstructive pulmonary disease [21]. The sputum induction procedure produces a minimal fall in forced expiratory volume in one second which can be inhibited by pretreatment with salbutamol [17], and a slight fall in arterial oxygen saturation which was not clinically significant [21]. In spite of the fact that there is generally no evidence of obstructive reversible disease in patients with ILD, the present protocol included the administration of $\beta_{2}$-agonists with the intention of preventing any unexpected adverse effects of hypertonic saline.

The cell dispersion method was used to examine sputum [22]: fresh plugs of sputum without salivary contamination were selected, the cells in the sputum dispersed by mechanical disruption in dithiothreitol, cytospins prepared and the supernatant collected for the measurement of levels of fluid phase constituents [22]. This method had been found to be superior to processing whole sputum [23] and enabled flow cytometry to be applied in the examination of the cell suspension.

What are the possible future advantages of induced sputum as a clinical tool in the assessment of ILDs?

Induced sputum was first compared to BAL for the assessment of exposure to hazardous dust and the evaluation of pneumoconiotic patients (silica and hard metal workers) [13]. Several studies had been carried out in which only induced sputum was evaluated in subjects suspected of occupational exposures: eosinophil counts were performed in the induced sputum of asthmatic isocyanate-sensitized subjects [24] and the frequency of bronchial dysplasia was investigated in the sputum of previously exposed miners [25]. Other researchers had 
studied the relevance of asbestos bodies in spontaneous sputum production $[26,27]$. In evaluating silica- and hard metal-exposed workers, it was found that BAL and induced sputum specimens yielded similar quantitative and qualitative results in terms of the number of particles present in the samples and the chemical analysis of the particles. Thus, being as it is a safe and simple procedure, induced sputum may be an especially efficacious tool for the evaluation of workers with suspected silicosis or hard metal disease. In addition, the biological monitoring of workers exposed to toxic agents has gained increasing acceptance as a means of accurately determining exposure to toxic materials [28]. Exposure to metals (e.g. lead and cadmium) and solvents (e.g. toluene and trichloroethane) is estimated by measuring the chemical or its metabolite in the subject's blood, urine or exhaled air. Measurements of hazardous dust levels, however, have not yet been included in this protocol since exposure assessment has been based mainly on occupational history and environmental monitoring. The present findings raise the possibility that induced sputum may serve as a future biological monitoring method in the periodic physical examination of healthy workers exposed to hazardous dusts.

With regard to other ILDs of unknown aetiology, such as sarcoidosis and idiopathic pulmonary fibrosis, various authors have conducted studies in which the information provided by BAL was compared to that from induced sputum $[14,15]$. D'IPPOLITO et al. [15] showed that there was a higher percentage of lymphocytes in both BAL specimens and induced sputum from sarcoid patients compared to control subjects. However, it is known that lymphocytosis alone in BAL fluid is not discriminatory for sarcoidosis in so far as there are numerous other diseases (e.g. nonsarcoid ILD, multiple pulmonary infections, noninfectious identified pulmonary inflammation, and a variety of neoplasms involving the lung and bronchial hyperactivity) that also show increased numbers of lymphocytes in BAL fluid specimens [29]. It had been reported that sarcoidosis is a disease mediated by the accumulation of activated CD4+ lymphocytes [30-32]. Some reports showed the CD4/CD8 ratio to be helpful in distinguishing it from other diseases [33]. It was in this context that the subpopulations of T-lymphocytes in samples obtained by both BAL and induced sputum in 19 patients with pneumoconiosis [13] and 30 patients with ILD [14] were analyzed and compared. It was found that although the percentages of total CD3+, CD4+ and CD8+ were lower in samples from induced sputum compared to BAL, the proportions between these subsets were highly correlated in both samples.

The present data support the view that the distribution of T-cell subpopulations present in the samples recovered by induced sputum correlates well to those recovered by BAL and that induced sputum can effectively and noninvasively identify CD4+ inflammation in order to distinguish between sarcoidosis and other nongranulomatous ILDs. The present evidence contributes to the ongoing debate as to the predictive value of the CD4/CD8 ratio by supporting those investigators who claim that a high CD4/CD8 ratio has a high specificity $(>90 \%)$ and a sensitivity of $50-60 \%$, a positive predictive value of $76 \%$ and negative predictive values of $85 \%$ [33-35]. This is in opposition to reports which contend that there is a high variability in the CD4/ CD8 ratio among sarcoid patients [36].
An interesting finding in the present investigation of induced sputum was that the results support the concept of an uninterrupted recirculation of lymphocytes from mucosa-associated lymphoid tissue with its activated lymphoid follicles to effector sites in the integrated human mucosal immune system (reviewed in [37]). The population of lymphocytes in BAL fluid is known to comprise a dynamic balance between entry and exit of these cells from other compartments of the lung [38]. It is reasonable to assume that there is traffic of CD4+ lymphocytes from the bronchial lamina propria to the bronchoalveolar space in sarcoidosis in so far as it is known that CD4+ T-cells are more efficient in recirculation than other subsets, such as B-cells [39]. Indeed, recirculation between bronchial and gut mucosa can explain the recent demonstration of the accumulation of CD4+ T-cells in induced sputum in a subgroup of patients with Crohn's disease [16].

As for other nongranulomatous lung diseases (e.g. idiopathic pulmonary fibrosis, and hypersensitivity pneumonitis), very good correlations between CD4/CD8 subsets recovered by induced sputum and BAL were observed in patients with different diffuse lung infiltrations. Having found that a $\mathrm{CD} 4 / \mathrm{CD} 8$ ratio of $1>1$ is of prognostic value in the estimation of a favourable response to steroids, this capability bestows even further value to induced sputum testing [39].

Can induced sputum replace BAL? The authors contend that BAL should be performed preferentially in patients in whom it is not contraindicated. For those unable to undergo this procedure, the authors believe that induced sputum provide equally satisfactory information for purposes of diagnosis. In sarcoidosis, the updated criteria for identifying active disease are based on clinical symptoms, chest radiography/computed tomography scan, gallium scan, pulmonary function tests, BAL with transbronchial biopsy and serum markers. The authors propose herein another test that can be added to those recommended by the American Thoracic Society Board of Directors and the European Respiratory Society Executive Committee for the initial evaluation of patients with sarcoidosis, and present induced sputum as another marker of sarcoidosis activity in addition to those already proposed as being potential diagnostic aids or indices of activation [40].

In summary, the authors contend that analysis of T-cell subsets by means of induced sputum may be as helpful as bronchoalveolar lavage analysis in the diagnosis of sarcoidosis and that it is of prognostic value in patients with idiopathic pulmonary fibrosis for whom there are clinical contraindications to undergoing bronchoscopy or when, for any other reasons, tissue samples are not available. Before firm recommendations can be made, however, more studies are needed, comparing bronchoalveolar lavage and induced sputum in patients with interstitial lung disease.

Acknowledgements. The authors thank E. Eshkol for excellent editorial assistance.

\section{References}

1. Bickerman HA, Sproud EE, Barach AL. An aerosol method of producing bronchial secretions in human subjects: a clinical technique for detection of lung cancer. Dis Chest 1958; 4: 347-362. 
2. Yue WY, Cohen SS. Sputum induction by newer inhalation methods in patients with pulmonary tuberculosis. Dis Chest 1967; 51: 614-620.

3. Leigh TR, Hume C, Gazzard B, Parsons P, Hussain OAN, Collins JV. Sputum induction for the diagnosis of Pneumocystis carinii pneumonia. Lancet 1989; ii: 205-206.

4. Pizzichini E, Pizzichini MMM, Efthimiadis A, et al. Indices of airway inflammation in induced sputum: reproducibility and validity of cell and fluid phase measurements. Am J Respir Crit Care Med 1996; 154: 808-817.

5. Iridale MJ, Wanklyn SAR, Philips IP, Krausz T, Ind PW. Non-invasive assessment of bronchial inflammation in asthma: no correlation between eosinophilia of induced sputum and bronchial responsiveness to inhaled hypertonic saline. Clin Exp Allergy 1994; 24: 940-945.

6. Claman DM, Boushey AH, Liu J, Wong H, Fahy JV. The analysis of induced sputum to examine the effects of prednisone on airway inflammation in asthmatic subjects. J Allergy Clin Immunol 1994; 94: 861-869.

7. Lemmiere C, Pizzichini MMM, Balkissoon R, et al. Diagnosing occupational asthma: use of induced sputum. Eur Respir J 1999; 13: 482-488.

8. Peleman RA, Rytilya PH, Kips JC, Joos GF, Pauwels RA. The cellular composition of induced sputum in chronic obstructive pulmonary diseases. Eur Respir J 1999; 13: 839-843.

9. Stoller JK, Rankin AJ, Reynolds HY. The impact of bronchoalveolar lavage cell analysis and clinician diagnostic reasoning about interstitial lung diseases. Chest 1987; 92: 839-843.

10. Haslam PL, Turton CWG, Lukoskek A, et al. Bronchoalveolar lavage fluid cell counts in cryptogenic fibrosing alveolitis and their relation to therapy. Thorax 1980; 35: 328-339.

11. Fahy JV, Wong H, Liu J, Bously HA. Comparison of samples collected by sputum induction and bronchoscopy from asthmatic and healthy subjects. Am J Respir Crit Care Med 1995; 152: 53-58.

12. Maestrelli P, Saetta M, Di Stefano A, et al. Comparison of leukocyte counts in sputum, bronchial biopsies and bronchoalveolar lavage. Am Rev Respir Crit Care Med 1995; 152: 1926-1931.

13. Fireman E, Greif J, Bologovov E, et al. Evaluation of occupational lung diseases by induced sputum compared to bronchoalveolar lavage. Chest 1999; 11: 1720-1728.

14. Fireman E, Topilsky I, Greif J, et al. Evaluation of interstitial lung diseases by induced sputum compared to bronchoalveolar lavage. Respir Med 1999; 93: 827-834.

15. D'Ippolito R, Foresi A, Chetta A, et al. Induced sputum in patients with newly diagnosed sarcoidosis. Chest 1999; 115: 1611-1615.

16. Fireman Z, Osipov A, Kivity S, Kopelman Y, Sternberg A, Fireman E. The use of induced sputum in the assessment of pulmonary involvement in Crohn's disease. Am J Gastroenterol 2000; (in press).

17. Popov TA, Pizzzichini MMM, Pizzichini E, et al. Some technical factors influencing the induction of sputum for cell analysis. Eur Respir J 1995; 8: 559-565.

18. Pavord I. Sputum induction to assess airway inflammation: is it an inflammatory stimulus? Thorax 1998; 53: 79-80.

19. Wong HH, Fahy JV. Safety of one method of sputum induction in asthmatic subjects. Am J Respir Crit Care Med 1997; 156: 299-303.

20. Tarodo de la Fuente P, Romagnoli M, Godard P, Bousquet J, Chanez P. Safety of inducing sputum in patients with asthma of varying severity. Am J Respir Crit Care Med 1998; 157: 1127-1130.

21. Bhowmik A, Seemungal T, Sapsford RJ, Devalia JL, Wedzica JA. Comparison of spontaneous and induced sputum for the investigation of airway inflammation in chronic obstructive pulmonary disease. Thorax 1998; 53: 953-956.

22. Popov T, Gottschalk R, Kolendowich R, Dolovich J, Powers P, Hargreave FE. The evaluation of a cell dispersion method of sputum examination. Clin Exp Allergy 1994; 24: 778-783.

23. Spavenello A, Beghe B, Bianchi A, et al. Comparison of two methods of processing induced sputum: selected versus entire sputum. Am J Respir Care Med 1998; 157 : 665-668.

24. Maestrelli P, Calcagni PG, Saetta M, et al. Sputum eosinophilia after asthmatic responses induced by isocyanates in sensitized subjects. Clin Exp Allergy 1994; 24: 29-34.

25. Michaylov MA, Pressyanov DS, Kalinov KB. Bronchial dysplasia induced by radiation in miners exposed to ${ }^{222} \mathrm{Rn}$ progeny. Occup Environ Med 1995; 52: 82-85.

26. Teschler H, Thompson AB, Dollenkamp R, Konietzko N, Costabel U. Relevance of asbestos bodies in sputum. Eur Respir J 1996; 9: 680-686.

27. Sulotto F, Capellaro E, Chiesa A, Villari S, Bontempi S, Scansetti G. Relationship between asbestos bodies in sputum and the number of specimens. Scand J Work Environ Health 1997; 23: 48-53.

28. Rosenberg G, Harrison R. Biological monitoring. In: LaDou J, ed. Occupational and Environmental Medicine. 2nd Edn. Stamford, CT, Appleton and Lange. 1997; pp. 637-646.

29. Rosen Y, Vulentin JC, Perschuck LP, Silverstein E. Sarcoidosis: from the pathologist's vantage point. Pathol Аппи 1979; 14: 405-439.

30. Hunninghake GW, Crystal RG. Pulmonary sarcoidosis: a disorder mediated by excess helper T-lymphocyte activity at sites of disease activity. N Engl J Med 1981; 305: 429434.

31. Fireman EM, Topilsky MR. Sarcoidosis: an organized pattern or reaction from immunology to therapy. Immunol Today 1994; 15: 199-201.

32. Newman LS, Cecile RS, Maier LA. Sarcoidosis. $N$ Engl J Med 1997; 17: 1224-1225.

33. Winterbauer RH, Lammert J, Selland M, et al. Bronchoalveolar lavage cell population in the diagnosis of sarcoidosis. Chest 1993; 104: 352-361.

34. Costabel U. Sensitivity and specificity of BAL findings in sarcoidosis. Sarcoidosis 1992; 9 (Suppl. 1): 211-214.

35. Costabel U. CD4/CD8 ratios in bronchoalveolar lavage fluid: of value for diagnosing sarcoidosis? Eur Respir J 1997; 10: 2699-2700.

36. Kantrow SP, Meyer KC, Kidd P, Raghu G. The CD4/CD8 ratio in BAL fluid is highly variable in sarcoidosis. Eur Respir J 1997; 10: 2716-2721.

37. Brandtzaeg P, Farstad I, Guttorn H. Regional specialization in the mucosa immune system: primed cells do not always home along the same track. Immunol Today 1999; 6: 267-277.

38. Young AJ. The physiology of lymphocyte migration through the single lymph node in vivo. Semin Immunol 1999; 11: 73-83.

39. Fireman E, Vardinon N, Burke M, et al. Predictive value of response to treatment of T-lymphocytes subpopulations in idiopathic pulmonary fibrosis. Eur Respir $J$ 1998; 11 : 706-711.

40. Statement on Sarcoidosis. Joint Statement of the American Thoracic Society (ATS), the European Respiratory Society (ERS) and the World Association of Sarcoidosis and other Granulomatous Disorders (WASOG) adopted by the ATS Board of Directors by the ERS Executive Committee, February 1999. Am J Respir Crit Care Med 1999; 160: 736-755. 